\title{
Design Optimization of Light Metal Irrigation Channels
}

\author{
Honggang ZHENG \\ College of Water Resources and hydraulic engineering \\ Yunnan Agricultural University \\ Kunmin, China \\ ynhg61@126.com
}

\author{
Yanqiong LI \\ Yunnan Agricultural University Library \\ Kunming, China
}

\author{
Jianxin YU \\ Engineering Research Center of Science and \\ Technology of Land and Resources \\ Yunnan Agricultural University \\ Kunming, China
}

\begin{abstract}
The last stage canal is the last channel to transport water to the field irrigation in irrigation system. Because of the large number of last stage channels, reducing the loss of water transportation plays an important role in improving the water use efficiency of irrigation area. At present, most of the irrigation channels are traditional channels for building materials constructed by slurry, masonry, concrete and other materials. They are poor in resistance to temperature change and uneven foundation settlement, and are prone to cracks which cause a great loss of water. Through the analysis, a new type of light metal plate channel which can adapt to the deformation of foundation, not easy to crack and corrosion resistance is constructed. The results show that: the trapezoid transverse reinforced galvanized steel plate has better irrigation channel structure. Under the condition of strength and deformation, the thickness of the typical canal body is $\mathbf{2 m m}$, and the transverse reinforcement bar diameter is $16 \mathrm{~mm}$. Three transverse reinforcing bars per meter were installed on the irrigation channel of galvanized plate with the lightest in weight, the lowest in price, and the most economical investment.
\end{abstract}

Keywords-last stage channel; metal irrigation channel; design optimization

\section{INTRODUCTION}

Since ancient times, agriculture has been an important industry in China, and the vast majority of the total water consumption in the country is agricultural water. Agricultural water accounts for about $63 \%$ of the country's total water consumption, and irrigation water accounts for about $90 \%$ of the agricultural water. At present, the irrigation water in China is mainly transported to the field through the canal. Due to the design, quality and management problems of the channel, a lot of water is lost in the transportation. The effective utilization rate of irrigation water is less than $50 \%$, and the annual water loss is about 200 billion $\mathrm{m} 3^{[1-2]}$. At present, many channels of traditional channels for the construction of masonry, concrete and other materials, although its intensity is large, but its ability to resist the change of temperature, uneven settlement of foundation is poor, easy to crack, channel after cracking, the irrigation water loss of [3-15]; the traditional masonry and concrete canal wall thickness is thicker, $10 \sim 40 \mathrm{~cm}$, covers an area of large aqueduct; the need for additional pressure caused an increase in operating cost in plain area. The contradiction between supply and demand of cultivated land is very prominent in China. The per capita cultivated land area in the world is $4.8 \mathrm{mu}$, and the per capita cultivated land in China is less than $1.4 \mathrm{mu}$. Therefore, reducing the occupation of cultivated land in the channel construction is of great significance. To solve the above problems, we need to build a new type of thin-walled channel which can adapt to the deformation of foundation and not crack easily, so as to improve the efficiency of water use and reduce the occupation of the channel.

With the reduction of galvanized steel plate, the conditions for the irrigation of small channels in the field have been mature. The use of galvanized steel plate irrigation channel provides another solution to the low utilization rate of water resources in our country and the problem of taking up more arable land by traditional channels.

Galvanized steel plate irrigation channel adapts to the temperature change and resists the uneven settlement ability of the foundation. Due to the allowable deformation of Galvanized steel plate irrigation channel, appropriate deformation can be adjusted in the allowable range to adjust the destructive force caused by the uneven settlement and temperature change of the foundation. Therefore, it is not easy to crack galvanized steel plate irrigation channel, and the water loss is small.

The traditional channel occupies a lot of land, and the per capita cultivated land occupies less in our country, and the construction of a large number of traditional last grade channels will further reduce the area of cultivated land. Channel of galvanized steel sheet is small and the roughness is small. Under the same over water flow 
condition, the cross section is smaller. The application of galvanized steel plate irrigation channel can effectively reduce the occupation of cultivated land and alleviate the contradiction between man and land to a certain extent. Galvanized steel plate irrigation channel can be produced in the factory. The production process of the channel is simple, the production cycle is short, the quality is uniform and easy to control, and the production efficiency is high. In terms of construction efficiency, precast zinc plate channel is light in weight, convenient in installation and quick in construction. In the later stage of maintenance, if a section of galvanized steel plate irrigation channel is damaged during operation, it is easier to replace galvanized steel plate irrigation channel, and convenient for later maintenance. Galvanized steel plate irrigation channel also has the reusable characteristics that the traditional channels do not have, and galvanized steel plate irrigation channel can be recycled. It is of great application value to study galvanized steel plate irrigation channel.

\section{IRRIGATION CHANNEL CROSS SECTION DESIGN}

\section{A. typical the last stage irrigation channel basic parameters}

According to the relevant regulations, the length of the farm irrigation channel should be $400 \mathrm{~m}$ to $800 \mathrm{~m}$, and the distance between $100 \mathrm{~m}$ to $300 \mathrm{~m}$, the length of the agricultural canal is $800 \mathrm{~m}$, and the distance $200 \mathrm{~m}$. The net irrigation rate of the ten thousand mu in the paddy field is Q $1.39 \mathrm{~m}^{3} / \mathrm{s}$. It is calculated that under the above conditions, the design flow $\mathrm{Q}$ of the typical last stage channel is set to $0.039 \mathrm{~m}^{3} / \mathrm{s}$.

Field water utilization coefficient of 0.95 , channel water use coefficient of 0.90 , while the irrigation water use coefficient $=0.95 * 0.9=0.855$; the roughness is an important parameter in the design section, the galvanized steel plate irrigation channel research, refer to the concrete cement mortar precausions roughness, conservative value of 0.012 ; the channel bottom slope value $1 / 2000$.

\section{B. section size calculation of irrigation channel}

The irrigation channels are usually rectangular, trapezoidal, U-shaped cross-section, the U-shaped section of the hydraulic conditions are relatively good, but the production and installation more difficult, and the trapezoid production and installation more convenient, the main study of trapezoidal cross-section.

Figure 1 is a schematic diagram of the trapezoidal cross section, trapezoidal irrigation channel part of the formula is as follows:

Wetted area:

$$
A=(b+m h) h
$$

Wetted perimeter:

$$
X=b+2 h \sqrt{1+m^{2}}
$$

Hydraulic radius:

$$
R=\frac{(b+m h) h}{b+2 h \sqrt{1+m^{2}}}
$$

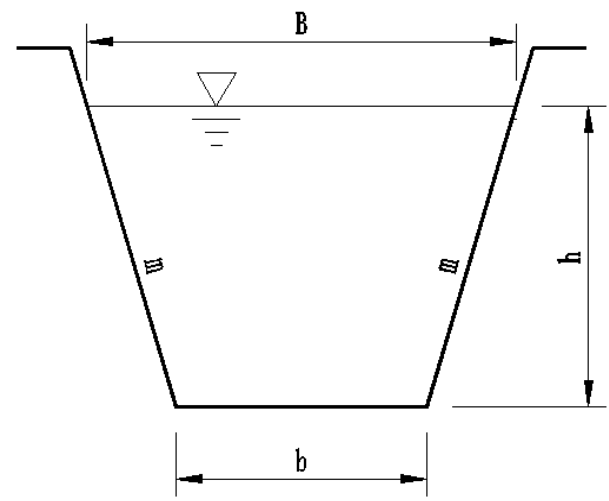

Figure 1. Trapezoidal section schematic.

The typical trapezoidal section of trapezoid is obtained by calculation. The depth of irrigation channel is $400 \mathrm{~mm}$, the width of irrigation channel top is $500 \mathrm{~mm}$ and the width of canal bottom is $250 \mathrm{~mm}$. The wall thickness of galvanized steel channel is determined to be $2 \mathrm{~mm}$. The specific size is shown in Figure 2.

According to the initial shape and size of the channel, the finite element software is used to carry out numerical simulation, and the internal force and deformation analysis are carried out.

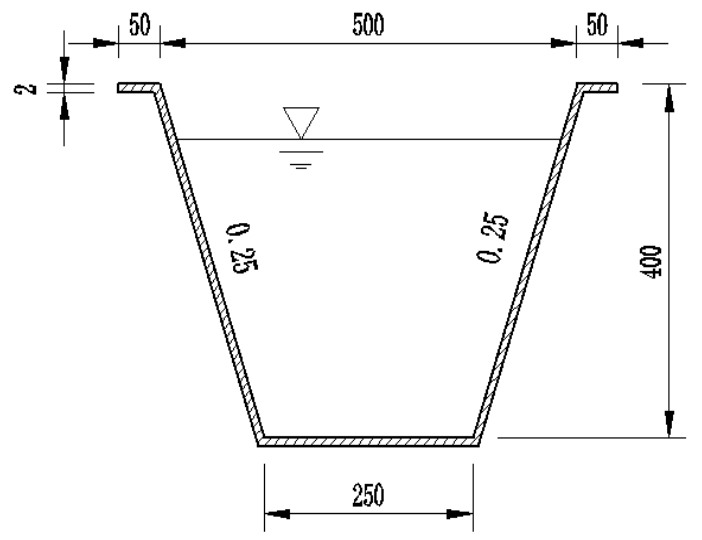

Figure 2. Design of irrigation channel for galvanized steel sheet. 


\section{NUMERICAL SIMULATION ANALYSIS OF IRRIGATION CANAL STRUCTURE}

Because the materials used for galvanized steel plate irrigation canal are quite different from traditional materials, the structure of traditional irrigation canal is not suitable for irrigation channels of galvanized steel sheet. Numerical simulation can effectively reduce the cost of structural design.

\section{A. parameter selection}

In the finite element analysis of this paper, the selection of unit type is SOLOD45. The SOLOD45 unit can be used to simulate the 3-D entity unit. The unit is composed of eight points, each of which has three degrees of freedom of the displacement direction of $\mathrm{X}, \mathrm{Y}$ and $\mathrm{Z}$. The unit has the characteristics of shaping, submersible and so on. The selected materials are carbon steel with specific parameters: the modulus of elasticity is $206 \mathrm{GPa}$, the Poisson's ratio is 0.28 , and the density is $7870 \mathrm{~kg} / \mathrm{m}^{3}$.

\section{1) Grid division}

The model is established in CAD, and the free mesh division method is used to divide the grid. The size of the grid is 0.01 .

\section{2) Load and boundary conditions}

The load of the irrigation channel is earth pressure and water pressure. According to the combination of the most unfavorable load combinations, the groundwater level is leveled with the ground line, the outlet is empty and the soil bulk density is $=1.3 \mathrm{~g} / \mathrm{cm}^{3}$. When loading is added, because the load is not uniformly distributed, the regional coordinate system is first defined at the lowest point of the model, and then the gradient load is applied. Because the load on both sides of the irrigation channel is symmetrical and the structure of the irrigation channel is symmetrical, it is assumed that the location of the symmetrical axis of the irrigation channel is fixed, and the surface of the symmetrical axis is constrained. The schematic diagram of the load is shown in Figure 3.

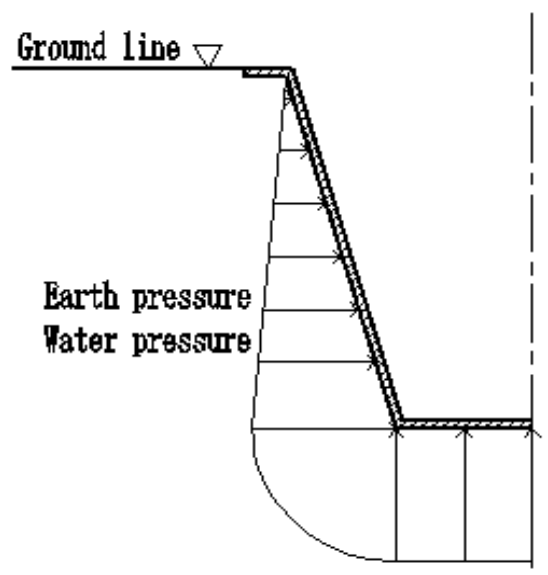

Figure 3. Load diagram.

\section{B. $\quad$ stress calculation}

According to the parameter setting, the software is used to calculate the model of the irrigation channel as the thickness of $2 \mathrm{~mm}$.

The maximum stress value is $15.6 \mathrm{MPa}$ when the thickness of galvanized steel plate is $2 \mathrm{~mm}$. The tensile strength of common carbon steel is from 300 to $400 \mathrm{MPa}$. Compared with the calculated results, the maximum stress of the galvanized steel plate when the thickness of the irrigation canal is $2 \mathrm{~mm}$ is $15.6 \mathrm{MPa}$, which is far from the tensile strength of the carbon steel. The tensile failure of the channel will not occur under the above load.

\section{C. lateral deformation calculation}

Under the same parameters, the lateral deformation of the irrigation channel of the galvanized steel plate is calculated. The deformation increases from bottom to top, and the bottom deformation of the model is the smallest, reaching the maximum at the top. This is because the force of the model is side pressure, which is equal to the bottom of the channel is fixed ends, the top is the free end, and the far away from the bottom is the maximum deformation at the top.

When the thickness of the irrigation channel of galvanized steel plate is $2 \mathrm{~mm}$, the maximum deformation amount is up to $62 \mathrm{~mm}$, and the lateral deformation is too large, and the requirement is not satisfied.

The irrigation channels galvanized steel plate thickness is $2 \mathrm{~mm}$ large lateral deformation, therefore, in the same load and constraint conditions, gradually increase the irrigation channel thickness, when the thickness of irrigation channels increased to $3.5 \mathrm{~mm}$, the lateral deformation meet the requirements, but the irrigation channel thickness of $3.5 \mathrm{~mm}$ will cause material waste, cost increase. In order to give full play to the performance of the material, the structure of the irrigation channel is further optimized with the reinforcement structure, so as to achieve the purpose of saving materials and reducing the cost.

\section{IRRIGATION CHANNEL STRUCTURE OPTIMIZATION}

\section{A. optimization objective}

Optimization should meet the constraints, to achieve the optimal design index. The mathematical model of optimal design is expressed as follows:

$$
\begin{array}{ll}
\min f(X) \quad X=\left[x_{1}, x_{2}, \cdots, x_{n}\right] \in R^{n} \\
\text { s.t. } & \mathrm{g}_{u}(X) \geq 0 \quad \mathrm{u}=1,2, \cdots m \\
& \mathrm{~h}_{v}(X)=0 \quad \mathrm{v}=1,2, \cdots p<n
\end{array}
$$

In the design of irrigation channels, the design variables may be selected as the thickness of the irrigation channel of galvanized steel plate $\mathrm{s}$, the number of transverse reinforcing ribs $\mathrm{n} 1$ in one meter length, the 
diameter $\mathrm{d} 1$ of transverse reinforcing ribs, and the length 11 of a transverse stiffener, that is,

$$
X=\left[s, n_{1}, d_{1}, l_{1}\right] .
$$

For this article galvanized steel irrigation channels for the lightest weight for the optimization goal, the objective function is as follows:

$$
\min f(X)=1.19 s+\frac{\pi d_{1}^{2} l_{1}}{4} n_{1}
$$

To sum up, under the conditions of strength and deformation, the target is the lowest cost of irrigation channels. The cost of irrigation canal is directly related to its weight. Therefore, under the condition that the stress does not exceed the tensile strength and the maximum allowable deformation, the thickness of irrigation canal is the smallest, the number of transverse reinforcement is the least, the weight of irrigation canal is the smallest, the price is the lowest, and the investment is the most economical.

\section{B. irrigation channel structure optimization}

The thickness of the irrigation channel wall of galvanized steel plate will increase the cost, and it also has some difficulties in the process of processing. If the wall thickness is too small, the strength is poor, and the corrosion cannot meet the requirements of actual use.

Through calculation and analysis, it is found that when the thickness of irrigation canal is $2 \mathrm{~mm}$, the deformation is too large. The transverse stiffener structure is optimized for the galvanized steel irrigation channel, and the transverse reinforcing bar is set up. Three transverse reinforcing bars per meter are set up, and the transverse reinforcement diameter of the steel bar is $16 \mathrm{~mm}$.

When the transverse reinforcement is set up, the top of the lateral deformation channel of the galvanized steel plate irrigation channel is the largest and the bottom is the smallest. When the transverse reinforcement is set up, the maximum deformation of the irrigation channel is reduced from $62 \mathrm{~mm}$ to $12 \mathrm{~mm}$, and the deformation meets the requirement.

\section{Irrigation channels transverse ribs number and diameter optimization}

1) The influence of the change of the number of transverse reinforcement on the deformation of irrigation channels

The thickness of the irrigation channel is $2 \mathrm{~mm}$, and the number of transverse reinforcement per meter increases to four, and the transverse reinforcement diameter of the steel bar is $16 \mathrm{~mm}$. The deformation results are as shown in Figure 4.

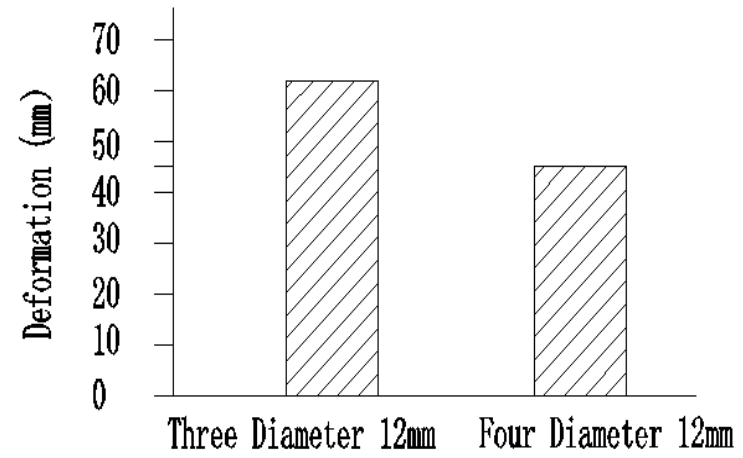

Figure 4. The influence of the number of transverse stiffeners on the deformation.

As can be seen from the figure, the increase of transverse stiffeners per meter of irrigation channels from three to four has no significant effect on the deformation, and the deformation decreases from $62 \mathrm{~mm}$ to $45 \mathrm{~mm}$.

2) The influence of transverse reinforcement diameter on the deformation of irrigation canal

The diameter of the transverse reinforcement is increased, and the diameter of the transverse reinforcement is changed from $12 \mathrm{~mm}$ to $16 \mathrm{~mm}$. The calculation results are shown in Figure 5.

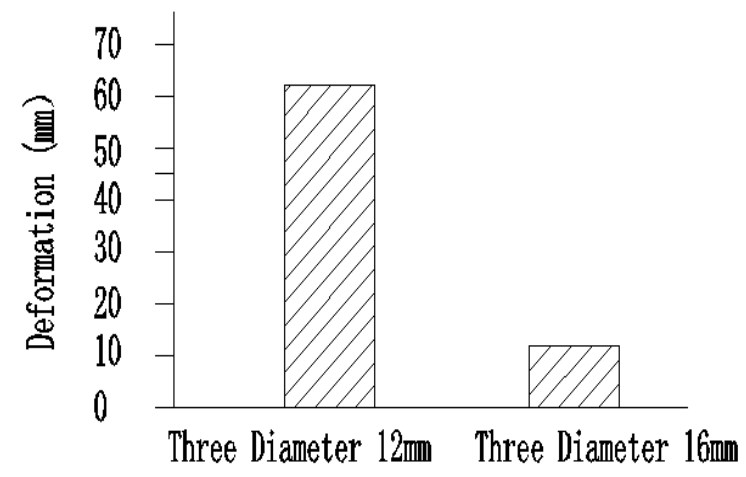

Figure 5. Influence of transverse reinforcement diameter on deformation.

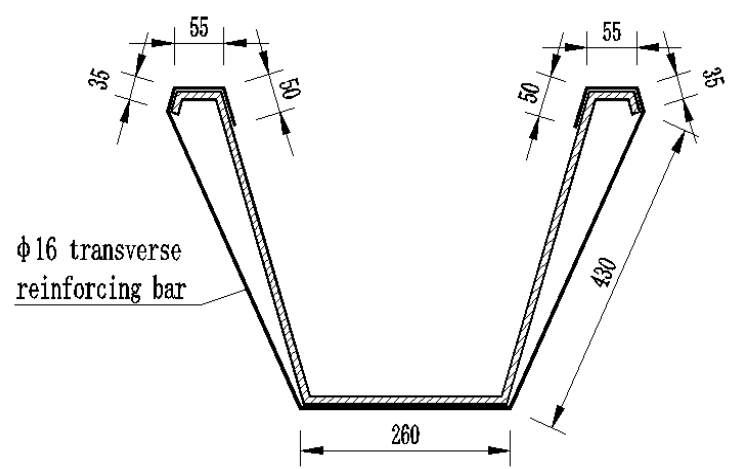

Figure 6. Design of irrigation channel for galvanized steel plate after optimization. 
When the transverse stiffener diameter increases to $16 \mathrm{~mm}$, the deformation of irrigation canal is $12 \mathrm{~mm}$. Changing the transverse reinforcement diameter ratio of irrigation canal than changing the number of transverse reinforcement have more significant influence on the deformation.

To sum up, the thickness of the irrigation channel of galvanized steel plate is $2 \mathrm{~mm}$, the diameter of transverse reinforcement is $16 \mathrm{~mm}$, and three transverse reinforcing bars per meter are more reasonable, which is closest to the optimization goal.

\section{CONCLUSION AND DISCUSSION}

\section{A. Conclusion}

(1) When the thickness of the irrigation channel of galvanized steel plate is $3.5 \mathrm{~mm}$, no transverse reinforcement is added and the weight is $32.70 \mathrm{~kg} / \mathrm{m}$, which satisfies the stress and deformation conditions at this time. After optimization, the thickness of irrigation canal is $2 \mathrm{~mm}$. There are three transverse reinforcing bars per meter, and the transverse reinforcement diameter is $16 \mathrm{~mm}$. At this time, the deformation of irrigation canal is $12 \mathrm{~mm}$, the weight of irrigation canal is $18.68 \mathrm{~kg} / \mathrm{m}$, and the weight of three transverse stiffeners is $6.6 \mathrm{~kg}$. The weight of irrigation channels was reduced by $7.42 \mathrm{~kg}$ per meter before optimization, and the weight of irrigation channels was reduced by $22.7 \%$.

(2) Galvanized steel irrigation channels in thickness relative to the masonry, concrete and other traditional irrigation channels have greater advantages. The traditional masonry and concrete irrigation channels have thick canal walls with a thickness of $100-400 \mathrm{~mm}$. The canal walls occupy a large area and occupy almost the same area as the over-water section of the irrigation channels. Some of the small-section irrigation channels occupy a large area Two-thirds, while the galvanized steel irrigation channel thickness is small, canal wall area is small, reducing the apparent effect of land.

\section{B. Discussion}

In this paper, the structure of the irrigation channel for the ladder type galvanized steel plate is optimized, but the irrigation channel of galvanized steel plate still needs further study in the aspect of frost resistance. This paper does not consider the resistance to frost heave of galvanized steel plate irrigation channels, and it is necessary to further analyze whether it can be applied to the cold areas in China.

\section{ACKNOWLEDGMENT}

This work is supported by the Fund Project: Land and Resources Public Welfare Research Fund Project "Wumeng mountain poverty alleviation land development key technology research and demonstration application" (201511003-3).

\section{REFERENCES}

[1] Z. Mingsheng, W. Feng, and Z. Guoping, "Problem s of agricultural water use in China and the strategies for saving water," Transactions of the CSAE, Supp, pp. 1-6,2005.

[2] W. Yitong, and G. Zonglou, "Some Understandings and Reflections on Irrigation Water Consumption in Large and Medium Irrigation Areas in South China," China Rural Water and Hydropower, pp. 2829, August 2016

[3] W. Jianjiang and S. Jiannan, "Main problems from design of channel with high groundwater level of Phase I of Mid-Route of South-toNorth Water Transfer Projectfor and their Countermeasures," Water Resources and Hydropower Engineering, vol. 45, pp.41-44, November 2014.

[4] Z. Mingguang, and SHi Jintang, "Elementary analysis of several problems in canal seepage control projec," Water Saving Irrigation, pp. 6-8, January 2003.

[5] Y. Wei, "Practice and application of anti-seepage in masonry lining," Science \& Technology Information, p. 122, May 2011.

[6] H. Hengli, and ZHao Dongli, "Application and popularization of canal seepage control technology," China Rural Water and Hydropower, pp. 62-63, June 2003.

[7] H. Wei,'Liu Qingming,Leng Xinghuo. Anti-seepageand drainage design for Taocha to Lushan section of South-to-North Water Diversion project," Yangtze River, vol. 45, pp.4-6, June 2014.

[8] C. Wenlong, "Genetic analysis on preventive measure against frost heaving damage and freeze expansion of concrete seepage control canal in Xin jiang," Techenical Supervision in Water Resources, pp. 45-47, March 2011.

[9] Z. Ru, and Wang Zhengzhong, "The progress of the research on the prevention and cure of the irrigation channel frozen injury in the seasonal frozen soil," Agricultural Research in the Arid Areas, vol. 25, pp. 236-240, March 2007.

[10] H. Wuquan, Z. Shuirong, and S Changyue, "Experimental study on composite insulating plasticboard of preventing Channel seepage and frost heave," Journal of Drainage and Irrigation Machinery Engineering, vol. 30, pp. 553-557, May 2012.

[11] D. CHangjun, "The north channel polyurethane insulation board of frost heave," China Water Transport, vol. 15, pp. 357-358, July 2015.

[12] Z. Xin, and L. Meng, Experimental Research on Polystyrene Board Heat-insulation for Channel in Panjin City," Water Saving Irrigation, pp. 25-27, December 2015.

[13] W. Xingguo, "Application of PE Closed-cell Foam Board and Polystyrene Foam Insulation Board in Canal Seepage Control Engineering," Energy Research and Mangement, pp. 70-72, February 2012.

[14] T. Yunfei, W. Keqin, and S. Weifeng, "Research on Optimal Design and method of Irrigation Channel," China Rural Water and Hydropower, pp. 58-60, April 2012.

[15] X. Xue, W. Xiugui, and Tan Dan, "Comparison of empirical formulas for calculating canal seepage loss," Engineering Journal of Wuhan University, vol. 49, pp. 365-371, March 2016. 